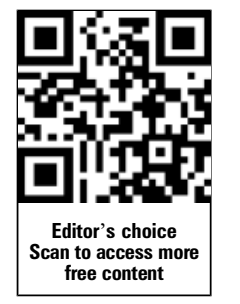

- Additional material is published online only. To view please visit the journal online (http://dx.doi.org/10.1136/ bjsports-2013-092380).

For numbered affiliations see end of article.

\section{Correspondence to} Torbjørn Soligard, Medical \& Scientific Department, International Olympic Committee, Lausanne 1007, Switzerland; torbjorn.soligard@olympic.org

Accepted 27 February 2013 Published Online First 20 March 2013
To cite: Engebretsen $\mathrm{L}$, Soligard T, Steffen K, et al. Br J Sports Med 2013:47:407-414

\title{
Sports injuries and illnesses during the London Summer Olympic Games 2012
}

Lars Engebretsen, ${ }^{1,2,3}$ Torbjørn Soligard, ${ }^{1}$ Kathrin Steffen, ${ }^{3}$ Juan Manuel Alonso, ${ }^{4}$ Mark Aubry, ${ }^{5}$ Richard Budgett, ${ }^{1}$ Jiri Dvorak, ${ }^{6,7}$ Manikavasagam Jegathesan, 8,9,10 Willem H Meeuwisse, ${ }^{11}$ Margo Mountjoy, ${ }^{12}$ Debbie Palmer-Green, ${ }^{13}$ Ivor Vanhegan, ${ }^{14}$ Per A Renström ${ }^{15}$

\section{ABSTRACT}

Background The Olympic Movement Medical Code encourages all stakeholders to ensure that sport is practised without danger to the health of the athletes. Systematic surveillance of injuries and illnesses is the foundation for developing preventive measures in sport. Aim To analyse the injuries and illnesses that occurred during the Games of the XXX Olympiad, held in London in 2012.

Methods We recorded the daily occurrence (or nonoccurrence) of injuries and illnesses (1) through the reporting of all National Olympic Committee (NOC) medical teams and (2) in the polyclinic and medical venues by the London Organising Committee of the Olympic and Paralympic Games' (LOCOG) medical staff. Results In total, 10568 athletes (4676 women and 5892 men) from 204 NOCs participated in the study. NOC and LOCOG medical staff reported 1361 injuries and 758 illnesses, equalling incidences of 128.8 injuries and 71.7 illnesses per 1000 athletes. Altogether, $11 \%$ and $7 \%$ of the athletes incurred at least one injury or illness, respectively. The risk of an athlete being injured was the highest in taekwondo, football, BMX, handball, mountain bike, athletics, weightlifting, hockey and badminton, and the lowest in archery, canoe slalom and sprint, track cycling, rowing, shooting and equestrian. 35\% of the injuries were expected to prevent the athlete from participating during competition or training. Women suffered $60 \%$ more illnesses than men (86.0 vs 53.3 illnesses per 1000 athletes). The rate of illness was the highest in athletics, beach volleyball, football, sailing, synchronised swimming and taekwondo. A total of 310 illnesses (41\%) affected the respiratory system and the most common cause of illness was infection ( $n=347,46 \%$ ).

Conclusions At least $11 \%$ of the athletes incurred an injury during the games and $7 \%$ of the athletes' an illness. The incidence of injuries and illnesses varied substantially among sports. Future initiatives should include the development of preventive measures tailored for each specific sport and the continued focus among sport bodies to institute and further develop scientific injury and illness surveillance systems.

\section{INTRODUCTION}

According to the Olympic Charter, the codification governing the organisation and operation of the Olympic Movement, one of the main roles of the International Olympic Committee (IOC) is to encourage and support measures protecting the health of athletes. ${ }^{1}$ Systematic monitoring of injury and illness trends over long periods of time provides epidemiological data that are indispensable to identify and subsequently reduce injuries and illnesses in high-risk sports and disciplines. ${ }^{2}$ Thus, to maximise the health protection and benefits of elite athletes, as well as to minimise the direct and indirect costs associated with injury and illness, the early identification of athletes at a high risk and subsequent development and introduction of effective prevention tools are significant goals for the IOC.

As early as 1998, the Fédération Internationale de Football Association (FIFA) started to survey all injuries incurring during their competitions, ${ }^{3-8}$ and other major sports federations followed their lead. ${ }^{9-16}$ Based on these experiences, a group of experts, convened by the IOC, developed an injury surveillance system for multi-sport events. ${ }^{17}$ It was successfully implemented for the first time in the 2008 Beijing (surveillance of injuries only) ${ }^{18}$ and in the 2010 Vancouver Olympics (surveillance of both injuries and illnesses). ${ }^{19}$ We further developed and optimised it for the Games of the XXX Olympiad, held in London in 2012 (hereafter referred to as the 'London Games').

With almost 11000 athletes from 204 countries, the London Games was one of the largest sports events ever. The aim of the present paper is to analyse the injuries and illnesses that occurred in London, with the long-term aim to enable the National Olympic Committees (NOCs) and International Federations (IF) to improve their work on protection of their athletes' health. Practical implications and suggestions for further research to protect the athletes' health are provided.

\section{METHODS}

We employed the IOC injury and illness surveillance system for multisport events to record injuries and illnesses in the present study. ${ }^{18}{ }^{19}$ First, we asked all NOC head physicians to report the daily occurrence (or non-occurrence) of newly sustained injuries and illnesses on a standardised form. Second, we retrieved the same information on all athletes treated for injuries and illnesses in the polyclinic and medical venues by the London Organising Committee of the Olympic and Paralympic Games' (LOCOG) medical staff.

\section{Implementation}

We informed the NOCs about the study in a letter sent 4 months in advance of the Olympic Games. 
The day before the opening of the Games, we invited the medical staff of the NOCs to a meeting covering the details of the study. In this meeting, we also started the distribution of the daily injury and illness report forms, as well as an instructional booklet detailing the study protocol.

Throughout the data collection, we recorded the response rate of NOCs having more than 30 participating athletes, and frequently visited these to encourage continuous medical reporting throughout the games.

\section{Definition of injury and illness}

We defined injuries and illnesses as new (pre-existing, not fully rehabilitated conditions were not recorded) or recurring (athletes having returned to full participation after a previous condition) musculoskeletal complaints or concussions (injuries) or illnesses incurred during competition or training during the London Olympic Games (27 July-12 August 2012) receiving medical attention, regardless of the consequences with respect to absence from competition or training. ${ }^{17}$ Injuries and illnesses occurring in football were recorded 25 July onwards, the opening date of the football competition. In cases where a single incident caused multiple injury types or affected multiple body parts, we recorded only the most severe diagnosis. ${ }^{17} 1920$

\section{Injury and illness report form}

The injury and illness report form was identical to the one introduced in the XXI Olympic Winter Games in Vancouver in $2010 .{ }^{19}$ With respect to injuries, we recorded the following information: accreditation number, sport and event, whether the injury occurred during competition or training, date and time, body part, type, cause and estimated time lost from competition or training. Likewise, we recorded the following information for illnesses: accreditation number, sport and event, date, diagnosis, affected system, main symptom(s), cause and estimated time loss.

We provided instructions on how to complete the form correctly in the instructional booklet. We distributed the injury and illness report forms to all NOCs in the following languages: English, French, Arabic, Chinese, German, Japanese, Russian and Spanish.

\section{Confidentiality and ethical approval}

We recorded and utilised the athlete's accreditation number to control for duplicates resulting from certain athletes being treated for the same condition by both the NOC and the LOCOG medical teams. In cases of duplicates, we retained the NOC data. We also used the accreditation number to query the IOC athlete database for the athletes' age, gender, nationality and sport. We treated all information with strict confidence, and anonymised our medical database at the end of the Games.

The study was approved by the medical research ethics committee of the South-Eastern Norway Regional Health Authority, Norway, and by the University College London Research Ethics Committee, UK.

\section{Data analysis}

We calculated the summary measure of injury and illness incidence (i) according to the formula $\mathrm{i}=\mathrm{n} / \mathrm{e}$, where $\mathrm{n}$ is the number of injuries or illnesses during competition, training or in total during the study period and e the respective number of exposed athletes. We calculated CIs of the relative risk (RR) of the number of injuries or illnesses between two groups by a simple Poisson model, assuming constant hazard per group. We present injury and illness incidences as means and rate ratios with $95 \%$ CIs. We regarded two-tailed $\mathrm{p}$ values $\leq 0.05$ as significant.

\section{RESULTS}

In total, 10568 athletes took part in the London Olympic Games. Of these, 4676 were women (44\%) and 5892 men $(56 \%)$.

\section{Incidence and distribution of injuries}

Among these athletes, we recorded a total of 1361 injuries, equalling an overall injury rate of 128.8 injuries per 1000 registered athletes (table 1). On average, $11 \%$ of the athletes sustained at least one injury $(n=1190)$. There were 114,18 and 7 athletes with two, three and four injuries, respectively. The risk of an athlete to be injured was the highest in taekwondo, football, BMX, handball, mountain bike, hockey, weightlifting, athletics and badminton (15-39\% of registered athletes were affected in each sport). The relative injury risk was the lowest for archery, canoe slalom and sprint, track cycling, rowing, shooting and equestrian (less than $5 \%$ of the athletes were injured). The injury rates in women (132.8 injuries per 1000 athletes (95\% CI 122.4 to 143.3$)$ ) and men (121.0 (112.1 to 129.9) was similar ( $R R=1.10$ (0.97 to 1.22$), p=0.11$ ) (table 2 ). However, male athletes were at significantly higher risk of injury in taekwondo $(\mathrm{RR}=1.9$ (1.1 to 3.5$), \mathrm{p}=0.03)$, whereas women were at higher risk of injury in football $(R R=1.7$ (1.2 to 2.2), $\mathrm{p}<0.001)$.

\section{Severity, location and type of injuries}

While two-thirds of the injuries were estimated to not result in any time loss from sport $(n=879,65 \%)$, a total of $482(35 \%)$ injuries were expected to prevent the athlete from participating in competition or training. It was estimated that $246(18 \%)$ injuries would result in an absence from sports for 1-3 days, 62 $(5 \%)$ in an absence for 4-7 days, $105(8 \%)$ in an absence for 8-28 days and $69(5 \%)$ in an absence for more than 28 days.

A total of 174 injuries (13\%) entailed an estimated absence from training or competition for more than 1 week (table 1). These injuries were 10 shoulder, elbow and knee dislocations (in hockey, football, judo, BMX and weightlifting); 38 muscle strains, of which 24 were thigh strains (mostly in athletics); 24 fractures (mostly in team sports; all body locations) and 6 stress fractures (4 in running events); 8 Achilles, knee and shoulder tendon ruptures (in athletics, badminton, handball and basketball); 47 ligament sprains (across all joints and sports) and 15 knee sprains, including 6 ACL and 1 PCL ruptures (in fencing, handball, judo, wrestling, badminton, table tennis, tennis and football). None of the six reported concussions ( 3 in football, 1 each in water polo, athletics and BMX) were classified as severe.

\section{Mechanisms and circumstances of injury}

The four most commonly reported injury mechanisms were overuse $(n=346,25 \%)$, non-contact trauma $(n=275,20 \%)$, contact with another athlete $(n=197,14 \%)$ and contact with a stationary object $(n=164,12 \%)$. Stratified by sport, overuse was the mechanism for $73 \%$ of all diving injuries, $34 \%$ of athletics and weightlifting injuries and $28 \%$ and $26 \%$ of swimming and fencing injuries, respectively. Non-contact trauma was a frequent mechanism in tennis (48\% of all tennis injuries), beach volleyball and canoe sprint (43\% each), fencing (39\%), badminton (35\%) and athletics (28\%). In contrast, more than $40 \%$ of the injuries in basketball, football, handball and judo were caused by contact with another athlete. Of all overuse injuries, 234 
Table 1 Rates of overall injuries, injuries leading to time loss ( $\geq 1$ or $>7$ days of estimated absence), competition and training injuries and overall illnesses in the Olympic sports

\begin{tabular}{|c|c|c|c|c|c|c|c|}
\hline \multirow[b]{2}{*}{ Olympic sport } & \multirow[b]{2}{*}{ Athletes (n) } & \multicolumn{5}{|l|}{ Injuries } & \multirow[b]{2}{*}{ All illnesses } \\
\hline & & All & $\geq 1$ day & $>7$ days & Competition & Training & \\
\hline Archery & 128 & $2(1.6)$ & $0(0.0)$ & $0(0.0)$ & $0(0.0)$ & $1(100.0)$ & $10(7.8)$ \\
\hline Athletics & 2079 & $368(17.7)$ & $145(7.0)$ & $59(2.8)$ & $133(39.5)$ & $204(60.5)$ & $219(10.5)$ \\
\hline \multicolumn{8}{|l|}{ Aquatics } \\
\hline Diving & 136 & $11(8.1)$ & $5(3.7)$ & $2(1.5)$ & $2(25.0)$ & $8(75.0)$ & $7(5.1)$ \\
\hline Swimming & 931 & $50(5.4)$ & $7(0.8)$ & $1(0.1)$ & $13(31.0)$ & $29(67.0)$ & $68(7.3)$ \\
\hline Synchronised swimming & 104 & $14(13.5)$ & $4(3.8)$ & $0(0.0)$ & $2(20.0)$ & $8(80.0)$ & $13(12.5)$ \\
\hline Water polo & 260 & $34(13.1)$ & $13(5.0)$ & $0(0.0)$ & $26(78.8)$ & $7(21.2)$ & $21(8.1)$ \\
\hline Badminton & 164 & $26(15.9)$ & $7(4.3)$ & $4(2.4)$ & $11(47.8)$ & $12(52.3)$ & $5(3.0)$ \\
\hline Basketball & 287 & 32 (11.1) & $10(3.5)$ & $7(2.4)$ & $21(75.0)$ & $7(25.0)$ & $9(3.1)$ \\
\hline Beach volleyball & 96 & $12(12.5)$ & $2(2.1)$ & $0(0.0)$ & $6(54.5)$ & $5(45.5)$ & $18(18.8)$ \\
\hline Boxing & 283 & $26(9.2)$ & $9(3.2)$ & $1(0.4)$ & $16(72.7)$ & $6(27.3)$ & $18(6.4)$ \\
\hline Canoe slalom & 83 & $2(2.4)$ & $1(1.2)$ & $0(0.0)$ & $0(0.0)$ & $2(100.0)$ & $4(4.8)$ \\
\hline Canoe sprint & 249 & $7(2.8)$ & $1(0.4)$ & $0(0.0)$ & $3(50.0)$ & $3(50.0)$ & $14(5.6)$ \\
\hline \multicolumn{8}{|l|}{ Cycling } \\
\hline BMX & 48 & $15(31.3)$ & $5(10.4)$ & $2(4.2)$ & $11(73.3)$ & $4(26.7)$ & $2(4.2)$ \\
\hline MTB & 76 & $16(21.1)$ & $8(10.5)$ & $2(2.6)$ & $5(31.3)$ & $11(68.7)$ & $5(6.6)$ \\
\hline Road & 210 & $19(9.0)$ & $7(3.3)$ & $2(0.9)$ & $14(73.7)$ & $5(26.3)$ & $7(3.3)$ \\
\hline Track & 167 & $5(3.0)$ & $3(1.8)$ & $0(0.0)$ & $1(20.0)$ & $4(80.0)$ & 16 (9.6) \\
\hline Equestrian & 199 & $9(4.5)$ & $4(2.0)$ & $2(1.0)$ & $6(100.0)$ & $0(0.0)$ & $11(5.5)$ \\
\hline Fencing & 246 & $23(9.3)$ & $10(4.1)$ & $2(0.8)$ & $10(45.5)$ & $12(54.5)$ & $13(5.3)$ \\
\hline Football & 509 & 179 (35.2) & $67(13.2)$ & $11(2.2)$ & $132(74.2)$ & $46(25.8)$ & $62(12.2)$ \\
\hline \multicolumn{8}{|l|}{ Gymnastics } \\
\hline Artistic & 195 & $15(7.7)$ & $8(4.1)$ & $4(2.1)$ & $8(66.7)$ & $4(33.3)$ & $5(2.6)$ \\
\hline Rhythmic & 96 & $7(7.3)$ & $1(1.0)$ & $0(0.0)$ & $1(16.7)$ & $5(83.3)$ & $1(1.0)$ \\
\hline Trampoline & 32 & $2(6.3)$ & $0(0.0)$ & $0(0.0)$ & $0(0.0)$ & $2(100.0)$ & $1(3.1)$ \\
\hline Handball & 349 & $76(21.8)$ & $32(9.2)$ & $16(4.6)$ & $55(75.3)$ & $18(24.7)$ & $17(4.9)$ \\
\hline Hockey & 388 & $66(17.0)$ & $25(6.4)$ & $10(2.6)$ & $44(71.0)$ & $18(29.0)$ & $29(7.5)$ \\
\hline Judo & 383 & $47(12.3)$ & $22(5.7)$ & $12(3.1)$ & $26(68.4)$ & 12 (31.6) & $16(4.2)$ \\
\hline Modern pentathlon & 72 & $6(8.3)$ & $2(2.8)$ & $0(0.0)$ & $3(60.0)$ & $2(40.0)$ & $1(1.4)$ \\
\hline Rowing & 549 & $18(3.3)$ & $2(0.4)$ & $0(0.0)$ & $7(53.8)$ & $6(46.2)$ & $40(7.3)$ \\
\hline Sailing & 380 & $56(14.7)$ & $3(0.8)$ & $1(0.3)$ & $30(62.5)$ & 18 (37.5) & $38(10.0)$ \\
\hline Shooting & 390 & $15(3.8)$ & $4(1.0)$ & $0(0.0)$ & $1(7.1)$ & $13(92.9)$ & $17(4.4)$ \\
\hline Table tennis & 174 & $11(6.3)$ & $7(4.0)$ & $2(1.1)$ & $7(70.0)$ & $3(30.0)$ & $12(6.9)$ \\
\hline Taekwondo & 128 & 50 (39.1) & $16(12.5)$ & $7(5.5)$ & $16(33.3)$ & $32(66.7)$ & $14(10.9)$ \\
\hline Tennis & 184 & $21(11.4)$ & $7(3.8)$ & $4(2.2)$ & $14(66.7)$ & $7(33.3)$ & $4(2.2)$ \\
\hline Triathlon & 110 & $16(14.5)$ & $8(7.3)$ & $3(2.7)$ & $11(73.3)$ & $4(26.7)$ & $7(6.4)$ \\
\hline Volleyball & 288 & $20(6.9)$ & $7(2.4)$ & $3(1.0)$ & $11(55.0)$ & $9(45.0)$ & $8(2.8)$ \\
\hline Weightlifting & 252 & $44(17.5)$ & $19(7.5)$ & $11(4.4)$ & $18(45.0)$ & $22(55.0)$ & $10(4.0)$ \\
\hline Wrestling & 343 & $41(12.0)$ & $11(3.2)$ & $6(1.7)$ & $20(62.5)$ & $12(37.5)$ & $16(4.7)$ \\
\hline Total & 10568 & 1361 (12.9) & $482(4.6)$ & 174 (1.6) & $684^{*}(54.9)$ & $561 *(45.1)$ & $758(7.2)$ \\
\hline
\end{tabular}

(68\%) were recorded with no estimated absence from competition or training.

The distribution of injuries during competition and training was similar, with 55\% occurring in competition and $45 \%$ during training. Injuries during training and in competition differed significantly in all injury characteristics (location, type, mechanism and subsequent time loss from sport) and in terms of the different sports (table 1). Seventy-five per cent of all injuries in team sports occurred in competitions, whereas $60 \%$ of all injuries in athletics were sustained during training. Furthermore, of the more severe injuries, entailing an estimated absence from training or competition of more than 1 week, $81 \%$ occurred during competition.

\section{Incidence and distribution of illnesses}

Among the 10568 athletes, a total of 758 illnesses were reported, resulting in an incidence of 71.7 illnesses per 1000 athletes (table 1). On average, $7 \%$ of the athletes incurred an illness. The incidence of illnesses was significantly higher in women compared to male athletes ( 86.0 vs 53.3 illnesses per 1000 athletes, $\mathrm{RR}=1.6$ (95\% CI 1.4 to 1.9 ), $\mathrm{p}<0.001$ ).

Illnesses were reported from a variety of sports. In athletics, beach volleyball, football, sailing, synchronised swimming and taekwondo, just over $10 \%$ of the athletes suffered from at least one illness (table 1). The peak in relative illness rates occurred in beach volleyball, where $19 \%$ of the players suffered from an illness during the Games. 
Table 2 Rates of overall injuries and injuries leading to time loss ( $>7$ days of estimated absence) in female and male athletes in the Olympic sports

\begin{tabular}{|c|c|c|c|c|c|c|}
\hline \multirow[b]{2}{*}{ Olympic sport } & \multicolumn{3}{|c|}{ Female athletes } & \multicolumn{3}{|c|}{ Male athletes } \\
\hline & $\mathrm{n}$ & All injuries & Time loss $>7$ days & $\mathrm{n}$ & All injuries & Time loss $>7$ days \\
\hline Archery & 64 & $1(2.6)$ & $0(0.0)$ & 64 & $1(1.6)$ & $0(0.0)$ \\
\hline Athletics & 991 & $164(16.5)$ & $29(2.9)$ & 1088 & $190(17.5)$ & $28(2.6)$ \\
\hline \multicolumn{7}{|l|}{ Aquatics } \\
\hline Diving & 68 & $4(5.9)$ & $0(0.0)$ & 68 & $5(7.4)$ & $1(1.5)$ \\
\hline Swimming & 450 & $26(5.8)$ & $1(0.2)$ & 481 & $24(5.0)$ & $1(0.2)$ \\
\hline Synchronised swimming & 104 & $14(13.5)$ & $0(0.0)$ & - & - & - \\
\hline Water polo & 104 & $9(8.7)$ & $0(0.0)$ & 156 & $25(16.0)$ & $0(0.0)$ \\
\hline Badminton & 78 & $11(14.1)$ & $3(3.8)$ & 86 & 15 (17.4) & $1(1.2)$ \\
\hline Basketball & 143 & $14(9.8)$ & $1(0.7)$ & 144 & $18(12.5)$ & $6(4.2)$ \\
\hline Beach volleyball & 48 & $5(10.4)$ & $0(0.0)$ & 48 & $7(14.6)$ & $0(0.0)$ \\
\hline Boxing & 36 & $7(19.4)$ & $0(0.0)$ & 247 & $18(7.3)$ & $1(0.4)$ \\
\hline Canoe slalom & 21 & $1(4.8)$ & $0(0.0)$ & 62 & $1(1.6)$ & $0(0.0)$ \\
\hline Canoe sprint & 90 & $3(3.3)$ & $0(0.0)$ & 159 & $4(2.5)$ & $0(0.0)$ \\
\hline \multicolumn{7}{|l|}{ Cycling } \\
\hline BMX & 16 & $5(31.3)$ & $0(0.0)$ & 32 & $10(31.3)$ & $2(6.3)$ \\
\hline MTB & 29 & $7(24.1)$ & $1(3.4)$ & 47 & $9(19.1)$ & $1(2.1)$ \\
\hline Road & 66 & $7(10.6)$ & $0(0.0)$ & 144 & $12(8.3)$ & $2(1.4)$ \\
\hline Track & 69 & $1(1.2)$ & $0(0.0)$ & 98 & $4(4.1)$ & $0(0.0)$ \\
\hline Equestrian & 77 & $4(5.2)$ & $1(1.3)$ & 122 & $4(3.3)$ & $1(0.8)$ \\
\hline Fencing & 124 & 7 (5.6) & $0(0.0)$ & 122 & $16(13.1)$ & $2(1.6)$ \\
\hline Football & 220 & $99(45.0)$ & $6(2.7)$ & 289 & $78(27.0)$ & $5(1.7)$ \\
\hline \multicolumn{7}{|l|}{ Gymnastics } \\
\hline Artistic & 97 & $6(6.2)$ & $2(2.1)$ & 98 & $9(9.2)$ & $2(2.0)$ \\
\hline Rhythmic & 96 & $8(8.3)$ & $0(0.0)$ & - & - & - \\
\hline Trampoline & 16 & $1(6.3)$ & $0(0.0)$ & 16 & $1(6.3)$ & $0(0.0)$ \\
\hline Handball & 171 & $45(26.3)$ & $10(5.8)$ & 178 & $31(17.4)$ & $6(3.4)$ \\
\hline Hockey & 192 & $33(17.2)$ & $4(2.1)$ & 196 & $34(17.3)$ & $6(3.1)$ \\
\hline Judo & 153 & 19 (12.4) & $3(2.0)$ & 230 & $25(10.9)$ & $8(3.5)$ \\
\hline Modern pentathlon & 36 & $1(2.8)$ & $0(0.0)$ & 36 & $4(11.1)$ & $0(0.0)$ \\
\hline Rowing & 196 & $8(4.1)$ & $0(0.0)$ & 353 & $10(2.8)$ & $0(0.0)$ \\
\hline Sailing & 143 & $22(15.4)$ & $1(0.7)$ & 237 & $33(13.9)$ & $0(0.0)$ \\
\hline Shooting & 159 & $11(6.9)$ & $0(0.0)$ & 231 & $4(1.7)$ & $0(0.0)$ \\
\hline Table tennis & 88 & $3(3.4)$ & $0(0.0)$ & 86 & $8(9.3)$ & $2(2.3)$ \\
\hline Taekwondo & 64 & $17(26.6)$ & $2(3.1)$ & 64 & $33(51.6)$ & $5(7.8)$ \\
\hline Tennis & 89 & $9(10.1)$ & $2(2.2)$ & 95 & $12(12.6)$ & $2(2.1)$ \\
\hline Triathlon & 55 & $10(18.2)$ & $1(1.8)$ & 55 & $6(10.9)$ & 2 (3.6) \\
\hline Volleyball & 144 & $11(7.6)$ & $3(2.1)$ & 144 & $9(6.3)$ & $0(0.0)$ \\
\hline Weightlifting & 103 & 16 (15.5) & $5(4.9)$ & 149 & $27(18.1)$ & $6(4.0)$ \\
\hline Wrestling & 76 & 10 (13.2) & $2(2.6)$ & 267 & $28(10.5)$ & $4(1.5)$ \\
\hline Total & 4676 & $621(13.3)$ * & $76(1.6)$ & 5892 & $713(12.1)$ * & $94(1.6)$ \\
\hline
\end{tabular}

Values are numbers (percentages) of injured athletes, unless otherwise indicated.

*Unknown gender for 27 injuries.

Affected system, causes, symptoms and severity of illness

A total of 310 illnesses (41\%) affected the respiratory system, and these were most frequently observed in athletics, beach volleyball, football, swimming and water polo $(3-5 \%$ of the athletes). In beach volleyball, $61 \%$ of the illnesses were reported to be respiratory infections. The second and third most affected systems were the gastrointestinal tract $(\mathrm{n}=123,16 \%)$ and dermatology $(\mathrm{n}=83,11 \%)$, respectively.

Concomitantly, infection was the most common cause of illness $(n=347,46 \%)$, affecting athletes in mainly the same sports as mentioned above. Symptoms of pain were present in $209(16 \%)$ of the illnesses. However, for a third $(248,33 \%)$ of all illnesses, symptoms were not reported.
Almost one in five illnesses $(n=145,19 \%)$ were expected to result in absence from training or competition. Of these, nine illnesses were expected to result in an estimated time loss of more than 7 days ( 7 cases of stress, fatigue and exhaustion; 1 upper respiratory tract infection and 1 instance of abdominal pain).

\section{Response rate and coverage of the athletes}

Seventy-four of the 204 NOCs had more than 30 participating athletes. Athletes from these NOCs comprised 9450 of the total 10568 athletes, corresponding to $89 \%$ (table 3). Throughout the 17 days of the London Games, the 74 NOCs submitted a 
Table 3 Response rates, injuries and illnesses in NOCs of different sizes (measured by number of athletes)

\begin{tabular}{|c|c|c|c|c|c|}
\hline & $<30$ & 30-99 & $100-200$ & $>200$ & All \\
\hline NOC (athletes) & $132(1114)$ & $37(1890)$ & $20(2510)$ & $15(5050)$ & $204\left(10564^{*}\right)$ \\
\hline Injuries (\%) & $256(23)$ & $308(16)$ & $380(15)$ & $416(8)$ & $1360+(13)$ \\
\hline Illnesses (\%) & $108(10)$ & $187(10)$ & $182(7)$ & $280(6)$ & $757 \ddagger(7)$ \\
\hline Report forms submitted§ (\%) & - & $624(97)$ & $332(93)$ & $248(97)$ & $1204(96)$ \\
\hline Injuries/illnesses reported by NOCs & $43 / 18$ & $163 / 105$ & $238 / 117$ & $291 / 190$ & $735 / 430$ \\
\hline Injuries/illnesses reported only by LOCOG & $213 / 90$ & $145 / 82$ & $142 / 65$ & $125 / 90$ & $625 / 327$ \\
\hline
\end{tabular}

total of 1204 of a maximum of 1258 forms (mean 96\%, range 12-100\%).

A total of 625 injuries (46\%) and 327 illnesses (43\%) were missed by the NOCs and only recorded by the LOCOG medical staff. Of the 174 severe injuries, meaning those with an estimated absence for more than 7 days, almost three-quarters were captured by the NOC $(n=123,71 \%)$, while 51 injuries $(29 \%)$ were reported solely through the medical encounters by the LOCOG medical staff.

\section{DISCUSSION}

This paper analyses and discusses the risk of injuries and illnesses among athletes competing in the London Olympic Games. The main findings of this 17-day long investigation were that $11 \%$ and $7 \%$ of all the 10568 athletes suffered from at least one injury or illness, with overall rates of 128.8 injuries and 71.7 illnesses per 1000 athletes, respectively. The magnitude and characteristics of the injuries and illnesses varied substantially between sports and gender. While taekwondo, football, BMX and handball had the highest rates of injury, the highest rates of illness were found in beach volleyball, synchronised swimming and football.

\section{Injury incidences in the lympic sports}

The injury incidences found across the sports in the London Olympic Games are comparable to those reported earlier from the Athens Olympic Games in 2004 (team sports only), ${ }^{4}$ the Olympic Games in Beijing in $2008,{ }^{18}$ as well as in certain major elite single-sport events. ${ }^{12}$ However, the London Games athletes competing in archery or boxing experienced a 5\% lower injury rate than their counterparts from the Beijing Olympic Games. ${ }^{18}$ Conversely, a higher injury rate was found among the London Games athletes competing in athletics (6\%), badminton (11\%), diving (6\%), fencing (7\%), handball (5\%), sailing (14\%), synchronised swimming (12\%), taekwondo (12\%), tennis (6\%) and triathlon (5\%). Similarly, the overall injury rate in athletics was 4-8\% higher than that previously reported from the athletics World Championships from 2007 to $2012 .^{13-15}$

A change in injury incidence can be the result of changes in competition rules, in equipment or in other environmental factors. Changes in injury rates can also follow an increased or reduced awareness among both the athletes and their medical staff in recognising and reporting even minor incidents (broad injury and illness definition applied in IOC surveillance studies). In certain sports, changes may also be attributable to more comprehensive and accurate data reporting by team physicians who over time have been trained as injury and illness recorders through the implementation of surveillance systems by their own Federation. Also, rate differences (lower or higher) may simply be the result of a natural fluctuation/variability of athletes exposure to risk, an observation that emphasises the value of on-going surveillance to monitor trends over time, for example, the effect of rule or equipment changes in the period between major sports events.

\section{Severity, location and type of injuries}

In the Olympic Games even minor injuries and illnesses with no or minimal time-loss can have serious consequences for the athlete. An injury or illness of otherwise insignificant severity may prevent Olympic athletes from reaching their life-time achievement. The majority $(65 \%)$ of the injuries occurring in the London Olympic Games were reported to be of minimal severity, with no absence from competition or training. In contrast, $35 \%$ of all injuries were estimated to entail time-loss of at least 1 day from training or competition, while $13 \%$ were estimated to have more than 7 days time-loss. This indicates a reduction in the number of time-loss injuries from the Beijing Games, where half of the injuries were expected to prevent the athlete from participating in competition or training. ${ }^{18}$ Furthermore, of the more severe injuries leading to an absence of more than 7 days, $81 \%$ occurred during competition, supporting earlier findings that the injury rate is higher in competition than in training. ${ }^{8} 1315{ }^{21}$ In addition, it might indicate the overall importance of Olympic competition over training; the former for many athletes representing the culmination of their perennial efforts, sacrifices and preparation to fulfil their ambitions as Olympians.

The sports with the highest rate of injuries entailing a prolonged absence from training or competition ( $>7$ days) were taekwondo (6\% of the athletes), handball (5\%), BMX cycling (4\%) and weightlifting (4\%). This corresponds with the data from the Beijing Games.

The risk of concussion is a recurrent concern in certain sports, and its diagnosis, prevention, treatment and return-to-play guidelines have been addressed in recent consensus meetings. ${ }^{22}{ }^{23}$ However, as in the Beijing Games (12 concussions, 1.09 per 1000 registered athletes), the risk of sustaining a concussion in the London Games was low (6 concussions, 0.57 per 1000 athletes). In contrast, 20 concussions (7.8 per 1000 participating athlete) were reported from the 2010 Vancouver Winter Olympic Games, with every fifth injury overall affecting the head, neck and cervical spine. ${ }^{19}$ Pending more data, this may indicate that winter sports athletes, particularly those exposed to high speed are at even higher risk of potentially 
severe head injuries than their summer-sports counterparts, including those competing in the martial arts.

\section{Mechanisms and circumstances of injury}

The mechanisms and circumstances of injuries in training and competition differed significantly among the different sports. Overall, the distribution of injuries across competition and training $(55 \%$ vs $45 \%)$ was similar to that reported in the 2011 world championships in athletics, ${ }^{15}$ but more proportionate than those reported from the Beijing Games (74\% vs 26\%, respectively) and from other single-sport events. ${ }^{8} 13$ The majority of injuries were reported to be acute, whereas overuse injuries with either a gradual or sudden onset accounted for a quarter of the injuries. Although a similar distribution was reported from the Games in Beijing, these numbers should be interpreted with caution, owing to the current limitations in the recording of overuse injuries. ${ }^{24}$

\section{Illness risk during the Olympics}

The impact of an illness on an athlete's competition and training can be just as significant as that of an injury. In recognition of this, the IOC and other major International Sports Federations, such as FIFA, FINA (Fédération Internationale de Natation) and IAAF (International Association of Athletics Federations) have extended their athlete health surveillance to also include illnesses.

Interestingly, the rate of illness in the London Games was identical to that of the Vancouver Winter Games, with 7 of 100 athletes being affected during the Games period. Similarly, sport-specific illness rates were comparable to those reported previously in aquatics (7\% in London vs $7 \%$ in recent championships), ${ }^{12}$ athletics $(11 \% \text { vs } 7 \%)^{15}$ and football $(12 \%$ vs $12 \%) .{ }^{8}$ Also consistent with the Vancouver data is the difference in the incidence of illnesses between female and male athletes, with women experiencing an illness incidence 60\% higher than men. The same disproportion has previously been reported in the 2009 athletics $^{13}$ and aquatics ${ }^{12}$ world championships, but not in the 2011 athletics world championships ${ }^{15}$ or during the 1994-2009 US Open tennis championships. ${ }^{25}$

The high incidence of respiratory infections mirrors data from other elite sport events. ${ }^{8} \quad 12 \quad 13 \quad 15 \quad 25$ Predominant risk factors are mechanical and dehydration stresses generated within the airways and the level of airborne pollutants, irritants and allergens inhaled by the athlete under high ventilatory exercise conditions. ${ }^{26}$ It has earlier been reported that airway hyperresponsiveness/asthma is the most common chronic medical condition experienced by both summer and winter Olympic athletes. $^{27}$

\section{Methodological considerations}

In studies on sports injury, it is usually recommended to express incidences using time exposed to risk as the denominator. ${ }^{20} 28$ However, given the inherent complexity of the Olympic Games, this was rendered not feasible in the present study. Instead we expressed the incidence of injury or illnesses as the number of new cases per 1000 athlete participants. Although this is the recommended approach in multisport events such as the Olympic Games, ${ }^{17}$ it ignores the fact that a multisport event is comprised of different frequencies and lengths of competition for each sport. For example, an Olympic diver's exposure to competition and training-and the encompassing risk of injury or illness-is by nature different to that of a sailor, weightlifter or footballer. Although interpretation of differences in injury incidence or pattern therefore should be made with some caution, our reported incidences do indicate athletes' actual risk of suffering injuries or illnesses in their respective sport.

We defined injuries and illnesses as new or recurring injuries or illnesses receiving medical attention, regardless of the consequences with respect to absence from competition or training. By using such a definition, predominantly the moderate and severe acute injuries will be recorded. The less-serious injuries may be overlooked, since such injuries do not always require medical attention, ${ }^{29} 30$ albeit our results show that the majority of reported injuries were not estimated to entail any absence from the sport. In the Olympic Games, all athletes can get healthcare through the athletes' village polyclinic and the venue medical clinics. However, the availability, size and quality of the NOCs own medical teams vary between countries, meaning that not all athletes benefit from the same easy access to healthcare, which may bias the injury and illness recording. Nonetheless, we believe that our collection of data through both the NOCs and LOCOG physicians, we captured most injuries and illnesses.

Throughout the 17 days of data collection in the Olympic Games, we collected $96 \%$ of all the NOC injury and illness report forms. This is the highest NOC response rate to date in the Olympic Games injury and illness surveillance, a result which can be attributed to favourably disposed NOC medical staff, an informational meeting with all NOCs the day before the Games' opening, the preparation of report forms in eight languages and an instructional booklet on how to fill in the forms, and a dedicated research team which conducted frequent follow-up visits to boost NOCs' compliance. However, although the NOC response rate was very high, we did not test the accuracy and internal validity of their reported data. Thus, we cannot know the extent to which the NOC data match the actual circumstances of the occurred injury or illness. An indication of this is that a number of injuries and illnesses were recorded in an incomplete manner with missing information in categories such as type, location and diagnosis. Furthermore, it has been documented previously in professional alpine skiing ${ }^{16}$ and male elite football ${ }^{31}$ that prospective injury surveillance by team medical staff underestimates the incidence of injuries and timeloss injuries. Our results support these findings; compared with the medical staff working at the polyclinic and medical venues, the NOC medical teams did not report $46 \%$ of the injuries, $29 \%$ of the time-loss injuries and $43 \%$ of the illnesses. With respect to the more severe injuries the results were somewhat better; of the 174 injuries with an estimated absence of more than 7 days, almost three-quarters were captured by the NOCs. Retrospective athlete interviews at the end of the event have been suggested as one option to improve the surveillance data quality ${ }^{15}$; however, this seems impractical in major events comprising thousands of athletes, such as the Olympic Games.

Recent papers from $\mathrm{Bahr}^{24}$ and Clarsen et al ${ }^{32}{ }^{33}$ highlight the inadequacy of the current standard epidemiological methodology to record the true magnitude and pattern of overuse injuries in sport. As pointed out by Bahr, ${ }^{24}$ overuse injuries may in many sports represent as much of a problem as do acute injuries, but these injuries are seldom properly captured or registered in statistics through current recording methods, as athletes with overuse problems often do not seek medical attention or lose time from training or competition. In the present study, overuse was reported to be the mechanism for every fourth injury, notably in diving, athletics, weightlifting, swimming and fencing. Furthermore, $68 \%$ of the overuse injuries in London were recorded with no estimated absence, an indication thatalso in the Olympic setting-athletes with overuse problems often continue to train and compete, although typically with 
significant inhibitions, such as pain, restricted function and reduced performance.

\section{Practical implications}

The continuous surveillance of injury and illness rates is a fundamental pre-requisite to athlete health protection. Only by monitoring the development over several years can we identify and follow changes in potential risk factors and mechanisms of injury and illnesses in the different sports and their disciplines, which, in turn, will allow us to develop, introduce and update targeted preventive measures. The key to a successful study of epidemiology lies in a well-organised data-collection procedure with coordinated efforts from sports medicine professionals, coaches and athletes, combined with systematic subsequent analyses.

However, surveillance of injuries and illnesses for elite athletes during multisport events such as the Olympic Games is subject to other challenges than surveillance systems in other contexts, such as single sport or amateur events. Differences encompass: the limited data-collection window; the great amount of data to be recorded and processed very quickly; the vast array of people-with different professional backgroundsinvolved in the same data-recording process; the high number of different specific settings in which the injuries occur (eg, canoeing vs tennis vs taekwondo); the low level of severe health incidents, with most being minor-to-moderate musculoskeletal conditions and the intense media and public scrutiny of injuries and illnesses when the athletes fail to meet their performance goals. ${ }^{34}$ The IOC injury and illness surveillance system has been continuously improved to best tackle these unique conditions, and we aim to continue to further refine its processes.

For example, a long-term goal of the IOC is to develop a customised electronic health record (EHR) that (1) can be used by NOCs on both a general year round basis in the clinic to record and follow athletes' health/injury, employing periodic health evaluations (PHE) recommendations, ${ }^{35}$ and in the lead up to and during the Olympic Games; (2) can be used at the Olympic Games' polyclinics and venue medical centres to have an immediate medical history of the athlete, which can be taken into consideration to optimise the treatment of injuries and illnesses during the Olympic Games and (3) will provide the IOC and other users with longitudinal de-identified individual and aggregate data allowing the IOC to survey and assess the epidemiology, identify injury and illness risk factors and mechanisms, and in turn, introduce tailored measures to prevent injuries and illnesses in athletes in all sports. We believe that instituting an EHR in the Olympic Movement can have a tremendous impact on athletes' health protection. Furthermore, it would also remedy the current recording problem of overuse injuries. By adopting the recommendations of Bahrre and Clarsen $e a^{24}{ }^{32} 33$ the EHR would facilitate the prospective serial measurement and recording of athlete health and symptoms of pathology, using sensitive scoring instruments for pain and other overuse symptoms, and open up for reporting of both the incidence and prevalence of injuries.

The continuously accumulating evidence that injury and illness rates vary substantially between sports demonstrates the need for tailoring preventive measures to the specific context of each sport. Sport bodies such as the IOC, IFs and NOCs have a great responsibility to protect the health of their athletes. The Olympic Movement Medical Code encourages all stakeholders to take measures to ensure that sport is practised without danger to the health of the athletes and to minimise the risks of physical injury and psychological harm. For NOCs one evident way of achieving this is by introducing PHEs in their daily practice, which are instrumental in preventing injuries and illnesses, and hence, to protect the health of the athletes. For IFs, a critical component of this responsibility is the institution of a scientifically sound injury and illness surveillance system in all major events. Some sports federations, such as FIFA, FINA, FIS (Fédération Internationale de Ski), FIVB (Fédération Internationale de Volleyball), IAAF and UEFA (Union of European Football Associations) have put increasing efforts into working systematically and scientifically to protect their athletes' health. We encourage other IFs and sports organisations to follow their example.

\section{CONCLUSION}

Eleven per cent of the athletes incurred an injury during the London Olympic Games, and 7\% suffered from at least one illness. The incidences and characteristics of injuries and illnesses during training and competition varied substantially between sports and gender. Future initiatives should include the development of preventive measures tailored for each specific sport and the continued focus among sport bodies to institute and further develop scientific injury and illness surveillance systems.

\section{Author affiliations}

${ }^{1}$ Medical \& Scientific Department, International Olympic Committee, Lausanne, Switzerland

${ }^{2}$ Department of Orthopaedic Surgery, University of Oslo, Oslo, Norway

${ }^{3}$ Department of Sports Medicine, Oslo Sports Trauma Research Center, Norwegian School of Sport Sciences, Oslo, Norway

${ }^{4}$ International Association of Athletics Federations (IAAF), Monte Carlo, Monaco

${ }^{5}$ International Ice Hockey Federation (IIHF), Zurich, Switzerland

${ }^{6}$ Fédération Internationale de Football de Football Association (FIFA), Zurich, Switzerland

${ }^{7}$ FIFA Medical Assessment and Research Center (F-MARC) and Schulthess Klinik, Zurich, Switzerland

${ }^{8}$ Olympic Council of Asia (OCA), Hawalli, Kuwait

${ }^{9}$ Commonwealth Games Federation (CGF), London, UK

${ }^{10}$ Olympic Council of Malaysia (MAS), Kuala Lumpur, Malaysia

${ }^{11}$ Sport Injury Prevention Research Centre, University of Calgary, Alberta, Canada

${ }^{12}$ Fédération International de Natation (FINA), Lausanne, Switzerland

${ }^{13}$ Division of Orthopaedic and Accident Surgery, University of Nottingham, Nottingham, UK

${ }^{14}$ University College London, London, UK

${ }^{15}$ Stockholm Sports Trauma Research Center, Karolinska Institutet, Stockholm, Sweden

Acknowledgements The authors specially thank Professor Fares Haddad for his assistance with obtaining the UCL Research Ethics Committee approval. The authors also sincerely thank all the NOC medical staff contributing to the data collection: Dr Bensoultane Zaher (ALG), Dr Maria Stella Cristiano (ANG), Dr Hugo Rordriguez (ARG), Dr Peter Baquie and colleagues (AUS), Dr Alfred Engel (AUT), Dr Adrian Lorde (BAR), Dr Marc Vangrinsven (BEL), Dr Yauheni Lasitski (BLR), Dr Jose Alfredo Padilha (BRA), Dr Stefan Strugarov (BUL), Dr Robert McCormack (CAN), Dr Guoping Li (CHN), Dr Boubakary Sidiki (CMR), Dr Mauricio Serrato Roa (COL), Dr Boris Labar (CRO), Dr Jorge Pavel Pinos Rivero (CUB), Dr Vetvicka and Dr Heinz (CZE),

Dr Morten Storgaard (DEN), Dr Milton Pineda (DOM), Dr Flores and Dr Eimen (ECU),

Dr Mostafa Elmofty (EGY), Dr Ramon Olive (ESP), Dr Mihkel Mardna (EST),

Dr Ayalew Tilahun Beshahe (ETH), Dr Tommi Vasankari (FIN), Dr Philippe Levan

(FRA), Dr Eric Baye (GAB), Dr lan McCurdie and colleagues (GBR), Zurab

Kakhabrishvili (GEO), Dr Bernd Wolfarth (GER), Dr Angela El-Adas (GHA),

Dr Georgios Marinos and colleagues (GRE), Dr Hans Larsen (HAI), Dr Julian Wai

Chang (HKG), Dr Eva Villalta Rivera (HON), Dr Peter Balogh (HUN), Dr Sarla Rao (IND),

Dr Lotfali Pourkazemi (IRI), Dr Sean Gaine and colleagues (IRL), Dr Iftach Hetsroni

(ISR), Dr Antonio Pelliccia (ITA), Dr Warren Blake (JAM), Dr Takao Akama and

colleagues (JPN), Dr Sagit Bavaev (KAZ), Dr Julius Ogeto (KEN), Dr Won Hah Park

and colleagues (KOR), Dr Abdullah Ashour (KSA), Dr Liga Cirule (LAT), Dr German

Clénin (LIE), Dr Dalius Barkauskas (LTU), Dr Axel Urhausen (LUX), Dr Abdellali Sobhi

(MAR), Dr Ramlan Bin Abd Aziz (MAS), Dr Hugo Martinez (MEX), Dr Lucienne

Attard (MLT), Dr Predag Dabovic (MNE), Dr Barend Phillipus 'Ben' Viljoen (NAM),

Dr Cees-Rein van den Hoogenband (NED), Dr Abdulkadir Mu'azu and Dr Ibrahim

Gyaran (NGR), Dr Tonje Wåle Flørenes (NOR), Dr Lynne Coleman and colleagues 
(NZL), Dr Caleb Otto (PLW), Dr Hubert Krysztofiak and colleagues (POL), Dr Artur Teixerira Pergira De Castro (POR), Dr Kim Yong Thaek and colleagues (PRK), Dr Jose Correa (PUR), Dr Rachid Bouras (QAT), Dr Dan Florin Tanase (ROU), Dr Phatho Cele and colleagues (RSA), Dr Maxim Velichko (RUS), Dr Abba Diatta (SEN), Dr Ahtime and Dr Sherwin (SEY), Dr Cormac O'Muircheartaigh (SIN), Dr Dragan Radovanic (SRB), Dr German Clénin (SUI), Dr Branislav Delej (SVK), Dr Bo Berglund (SWE), Dr Hilary Meechai Inwood (THA), Dr Chou and Dr Chang (TPE), Dr Terry ALI (TRI), Dr Haj Romdhane M. R. and Dr Moncef Ben Abid (TUN), Dr Tugba Kocahan (TUR), Dr Abdulhameed Al Attar (UAE), Dr Olesandr Varvinskyi
(UKR), Dr Gonzalo Andrés Rodríguez Gómez (URU), Dr Chang and Dr Moreau (USA), Dr Elena Abaeva (UZB), Dr Marelia Guillen Mujica (VEN), Dr Nguyen Van Phu (VIE), Dr Nicholas Munyonga (ZIM).

\section{Competing interests None.}

Provenance and peer review Commissioned; internally peer reviewed.

- References to this paper are available online at http://bjsm.bmj.com

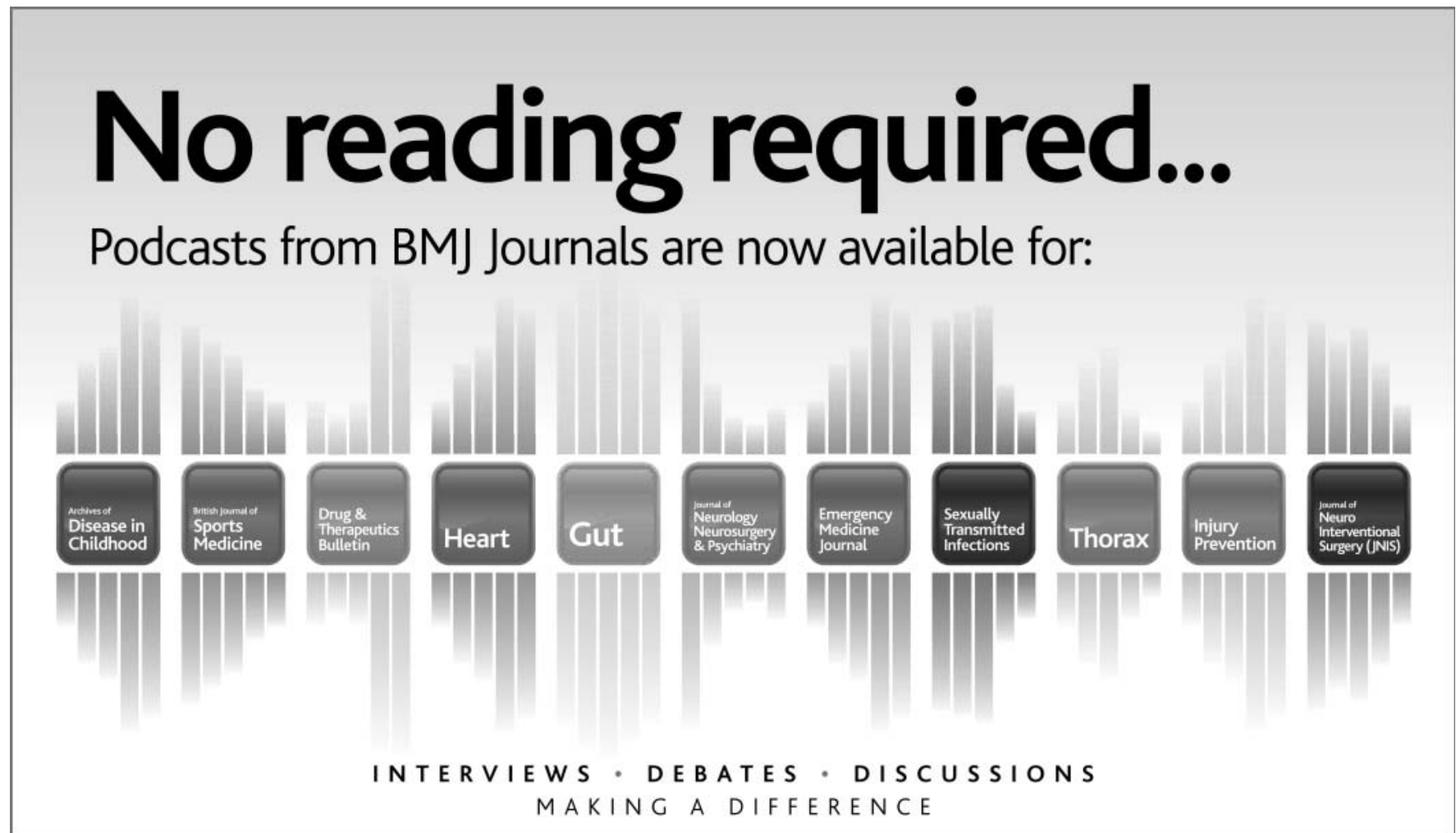

BMJIJournals

Listen now at podcasts.bmj.com 